\title{
Research on Idioms Translation between English and Chinese
}

\author{
Yu Sun ${ }^{1}$, Zhengjie $\mathrm{Li}^{2}$ \\ ${ }^{1}$ College of Humanities \& Sciences of Northeast Normal University, Chanchun130000, China; \\ ${ }^{2}$ University of South Florida, Tampa, USA.
}

Keywords: Translation; English idioms; Chinese idioms.

\begin{abstract}
Idioms are profound in both Chinese and English languages. A good command of idioms can be of benefits in language acquisition, especially for Chinese English learners. The free transition between English idioms and Chinese ones is necessary for interaction, no matter in written or daily social interactions. This paper observes how to make sense of idioms in both the English and Chinese languages by adopting distinguishing translation tactics, with the purpose of facilitating TESOL teachers as well as Chinese English learners upon learning and using idioms more effectively.
\end{abstract}

\section{Introduction}

From the Oxford Advanced Learners Dictionary of Current English, translation is defined as "a written or spoken rendering of the meaning of a word, speech, book, or other text, in other language"[1]. When the definition applies to the translation of idioms, it means the process of translating idioms from one language into another. Nugroho believes that "translation is an effort of finding equivalent meaning of a text into the second language" [2].The concept of equivalence is essential in the process of translation. One of the most famous translation theorists, Nida states that "translating consists in reproducing in the receptor language the closest natural equivalent of the source language message" [3]. Furthermore, Nida's notion of dynamic equivalence is well known among translation scholars and dynamic equivalence aims to present a complete naturalness of expression from one language to another. Thus, in the process of translating English idioms, other than translating word for word, students are expected to restore the original meaning from English to Chinese as much as possible, and never bypass the cultural connotation of an expression.

Indeed, for the Chinese students, translating idioms is a difficult task since not all English idioms can find their equivalents in Chinese idioms because of linguistic and cultural differences. However, with the help of effective translation tactics in translating English into Chinese, the Chinese students will manage using English idiomsnaturally in the appropriate contexts. Idioms, embedding much cultural information andmirroring national characteristics and environments, may help the Chinese students adapt to smooth interaction with native speakers, or an easier access to English readings. More importantly, through idiom learning, the Chinese students will not only enhance their linguistic ability, but develop their idiomatic appreciation in English, which may aid them to understand the double-voiced discourse when engaging in a conversation with native English speakers.

\section{Literature Review}

Wan, Kng, Wang, and Bond pose a question of how to preserve full information while maintaining the evoked senses in English-Chinese translation. Given the intrinsic syntactic differences, as well as cultural and semantic differences between languages, a perfect translation seems to be impossible in most cases. Thus, translators tend to use a non-idiomatic synonym to present the idiomatic expressions if they cannot find the equivalent version in the target language [4]. Chengyu is regarded as "Chinese idioms" with prototypical four characters and non-compositional phrases originated from historical lore or classical literature. Chengyu functions really well in the translation of English idioms that are culturally-specific as both Chengyu and English idioms are considered as "frozen" expressions and expressing a meaning not necessarily from the literal constituents. Since both Chengyu and English idioms have fixed and distinct meanings, it would be interesting to create an idiom database by pairing the English idioms with the equivalent Chengyu, and this 
database will serve as an important tool-kit for translators and language learners. In this way, even though the information cannot be fully transmitted from one language to another, people can still obtain the evoked senses from this type of translation.

Fotovatnia and Goudarzi pose a question asking how analyzability can affect the processing of the English idioms. Particularly, Fotovatnia and Goudarzi create three categories of idioms normally analyzable, abnormally analyzable, and unanalyzable, which are very similar to Liontas' Lexical-Level idioms, Semi-Lexical Level idioms, and Post-Lexical Level idioms [5]. Their study was based on analyzability, investigating among thirty Persian undergraduate students who have limited English knowledge and aims to see the speed and accuracy with which participants assigned each idiom. The results show that the Persian students, from the quantitative statistics, are able to capture the meaning of normally analyzable idioms more accurately and much faster than abnormally analyzable idioms and unanalyzable idioms, which indicates that analyzability of idioms is a matter of degree in an unfamiliar language. In other words, language learners tend to feel more challenged to process idioms that are abnormally analyzable or unanalyzable. Based on this research, in ESL or EFL classrooms, it is suggested that English teachers need to be aware of the analyzability of the idioms and they need to facilitate the process of translating the idioms into students' primary language and allow more time to let students figure out the definitions when the idioms are abnormally analyzable or unanalyzable. Moreover, English teachers are expected to present the cultural and historical information of the unanalyzable idioms so students can shorten the time to comprehend those idioms and associate the meaning from their L1.

Griffin presents the challenges of intercultural communication and international communication because of the pitfalls of translation and the less attention of the cultural knowledge. Griffin points out that even his African American students in his marketing class, through a quantitative study, are not able to interpret all of the selected popular 25 English idioms (verbally symbolic and figuratively symbolic) from mass media successfully due to the gap in understanding theses figurative idioms. By introducing the Babel Fish translator (http://world.altavista.com), Griffin brings the notion of Back-Translation to his students. He believes that, using this translator website, students will be able to enhance their international communication through the back-translated mode of English-foreign language-English. With both the usefulness and the limitation of the technology like Babel Fish translator, students can gradually realize the communicative gaps caused by the cultural differences in the international business while having fun with this creative tool. [6]

In this digital age, translation tools embedded on apps, websites, and software can be both effective and motivating for language learners. English teachers may find some online translation tools or translation apps and introduce them to English learners so they can use them when they are confused with English idioms. In this way, English learners, while translating the English idioms, will not only find the definitions from their primary language, but they will start thinking critically over the accuracy and the cultural appropriation of the translations, which may have a positive impact upon their linguistic and cognitive development. In the long run, students will become active decoders and translators.

Indeed, English idioms are the reflection of western culture and are reproduced with different groups and regions. Bearing this in mind, when translating English idioms to another language, translators don't have to be bilingual, but they should be bi-cultural and aware of how the cultural context interacts with the translation between languages. Since idioms are influenced by the culture and contexts, it is essential to develop idiomatic competence within the context of meaningful and authentic use. In terms of English idiom learning in the EFL/ESL context, appropriate translation methods and cultural context will allow English learners to comprehend the English idioms more effectively.

\section{Translation Tactics}

Being a king of recreation for art, idioms translation demonstrates its beauty as a scientific and philosophical poetry with deep meaning, euphonious tone, and vivid images. Before teaching students how to translate idioms between English and Chinese, it is important to make students understand the cultural differences between Chinese and English idioms. In other words, idiom translation is not only a linguistic 
conversion, but also the transplantation of culture [7]. Therefore, the Chinese translation of English idioms should be based on the consideration of the cultural differences between English and Chinese, and the translators need to comply with Nida's dynamic equivalence and present the translated idioms accurately and faithfully with the styles and images. Nevertheless, in the translating process, there may not always be a hundred percent equivalence from the source language to the target language. Nida states, "[n]o two words in any two languages are completely identical in meaning. This means that to some extent there is always some loss or skewing of meaning in inter-lingual communication. One purpose of translating is to keep such disparities at a minimum" [8].To achieve that, the TESOL teachers may introduce the following translation methods to the Chinese students when they are translating idioms between English and Chinese.

The first tactic is literal translation, which was introduced in Nida's Translation Theory in Language, Culture and Translating. Literal translation means that it complies with the original meaning of the expressions and does not create wrong association, and maintains the syntactic structure, the metaphorical meaning, and the imaginative analogy of English idioms [9]. Also, literal translation can retain the original cultural and national characteristics. Often, some idioms may have already been used in the target language, but most people do not even know that they were derived from other countries. Such idioms as "blood is thicker than water," "knowledge is power," “you cannot clap with one hand,” "easy come easy go,” "constant dropping wears away a stone," and so on and so forth, can all be translated directly into Chinese, the target language. Occasionally, idioms and proverbs in English can be traced to their analogous Chinese forms of expression and meaning exactly. In this way, the Chinese students, when seeing English idioms, can retrieve information through their L1 databases and comprehend the idioms effectively. So, literal translation can usually accurately reflect the complete representation of English idioms when the original is almost in accord with Chinese idioms in the form of vocabulary, grammar, and rhetorical uses. Obviously, through literal translation, students will obtain mental images of the meaning of the English idioms. Most idioms are catchphrases, such as “strike while the iron is hot” (趁热打铁) and “to add fuel to the fire” (火上浇油), which summarize the essence of human culture accumulation and touch on the basic human life, automatically allowing students to find the analogous synonyms in Chinese, such as etc.

The second tactic is free translation. As not all English idioms have Chinese equivalents, the strategy of literal translation may not be functional in presenting an accurate meaning of the English idioms. When taking cultural differences into consideration in the process of translating English idioms, students may get extremely confused when they are not able to find corresponding idioms in Chinese. Sometimes, "rigid literal translation will violate the readability of the translation, leading to the monotony of reading as well as the ineffective cultural transfer" [10]. What is even more challenging is that some anecdotes or legends in English idioms may elude the Chinese students' understanding. In this situation, the free translation method, after a detailed explanation in Chinese from the TESOL teacher, can reinforce students' understanding, especially when the Chinese students can associate with the similar Chinese idioms. For example, the Chinese idiom “一言既出, 驱马难追” meaning “one word let slip and four horses will fail to catch it” literally, can only be comprehended through free translation. The corresponding idiom in English should be "A word spoken is past recalling." Thereby, it is the same with English idioms, such as "keep one's nose clean," while the literal translation may fail to convey the exact idea accurately. In addition, English idioms like "she was born with a silver spoon in her mouth" (she was born in a rich family) and "Every family has at least one skeleton in the cupboard" (every family has its own trouble) may not be understood if translated literally. However, with the free translation strategy, students will bypass the monotony of reading and retain the original flavor and image of the English idioms. In a word, free translation allows the Chinese students to make the translating process more succinct and distinct and it is also a great method for them to avoid misunderstanding or being misled by English idioms.

The third tactic is borrowing translation. Though people from different countries may have different cultures and beliefs, humanistic values prevail universally and thanks to the internet, people are now all connected to share their personal feelings and social experiences across distances. So Chinese idioms and English idioms may still have something in common regardless of the language differences. In some occasions, expressions in different languages may not only contain similar literal meaning and image meaning, butalso 
present identical connotation. In other words, idioms from different languages may overlap in either literal meaning or image meaning that conveys the same cultural information. In this case, the Chinese students may use borrowing translation strategies to fulfill the purpose of mutual translation in such idioms. For example, the English idiom "practice makes perfect" can be converted to a Chinese Chengyu (four-letter words idiom in Chinese) “熟能生巧,” and the Chinese Chengyu “破釜沉舟” can be translated as "burn one's boats,” which originates from the military strategy of the two countries, so the usage and meaning are the same. Therefore, the Chinese students can still faithfully express the meaning of the original idioms by being creative to retrieve idioms data that can maintain the vivid image, the rhetorical effect and the ethic characteristics from their mind.

Last but not least, when translating English idioms, translators should adopt different translation methods in order to use the target language to restore the meaning. To achieve this goal, the integrated approach, "not only reproducing the literal meaning or figurative meaning so as to retain the style of the original text but also conveying the implicated meaning as well", can be used by the Chinese students to insure "faithfulness" and "smoothness" of the translation. Each translation method may have its own advantages and disadvantages and a full comprehension of certain idioms may involve much consideration of different ethnic characteristics and cultural information of two languages. Integrated approach is able to combine several methods to help students to better maintain the original information, form and style, and rhetoric coloring image of the source language. For example, “to live a dog's life” can be translated into “过牛马生活” “"to live a cow's or a horse's life” literally in Chinese), and “the milk is spilled” is equivalent to Chinese “木已成舟” (“the wood is already made into a boat" literally in Chinese). As the Chinese students' cognition and linguistic ability is growing, they will be able to utilize the integrated approachto help them translate English idioms more faithfully and accurately; meanwhile, theintegrated approach will guarantee the comprehension of the idioms and lead the Chinese students to foster bi-cultural awareness and appreciation.

\section{Conclusion}

It is universally accepted that both Chinese language and English language are profound in idioms. Therefore, idiom learning turns out an efficient way for language learners, especially when it comes to the cultural and historical differences between the English and Chinese languages. In the process of instilling the idioms into students, TESL teachers need to make studentsunderstand that some English idioms can be comprehended literally so the Chinese students need to learn how to analyze the syntactic structure of some common and easy English idioms. In other cases when the idioms are metaphorical, the teachers can encourage students to watch over the cultural context, which often tells the origins and transformation of idioms in course of time. Besides, Nida's "functional equivalence" is highly advocated in idiom translation, which depicts that from a semantic equivalence perspective, target language readers can achieve the same feeling with the source language readers. Similarly, an ancient Chinese scholar Yan Fu proposed Fidelity Theory, emphasizing "faithfulness, expressiveness, and elegance". Under the equivalence theory, many authors tend to have a unanimous agreement upon the following translation strategies: literal translation, free translation, borrowing translation, and integrated approach. Thus, when the Chinese students are not able to locate the equivalent expressions in their "database" for English idioms, the teacher needs to facilitate the process of translation by referring to those effective translation strategies, helping the Chinese students present the meanings accurately while retaining the original cultural characteristics of English idioms as much as possible.

As the effect of using cultural contexts and translation methods in English idioms learning is highly determined by English proficiency level and linguistic ability of English learners, we can hardly present a hasty conclusion that learning English idioms through cultural contexts and translation will apply to all Englishlearners, not to speak of other variables like teachers' qualifications, teaching methodology, and learning environment. Nevertheless, teaching English idioms through cultural contexts and translation will benefit the Chinese students as it sets language learning in a context where interactions and exchange of information take place. To further develop the Chinese students' idiomatic competence, the teachers are 
expected to align the syllabus and the content with the other subjects like literature, linguistics, and encourage the students to interact with foreigners or English language resources like literary works or audio-visual tracks, academically and socially. In this way, the Chinese studentswill reinforce their acquired English idioms in a meaningful and authentic environment. Furthermore, teachers can utilize many informal assessments like pair practice, translation exercises, and quizzes to reflect the learning progress among the Chinese students. The assessment and practice are supposed to facilitate students' learning and utilizing of idiom, which will further promote language learning in a big picture.

\section{References}

[1]. Hornby, A. S. (1974). Oxford advanced learners dictionary of current English. Oxford: Oxford University Press.

[2]. Nugroho, S. S. (2005). Meaning and translation. Yogyakarta State University. Retrieved from http://core.ac.uk/download/pdf/11062502.pdf

[3]. Nida, E. A. (1982). The theory and practice of translation. Leiden: E.J. Brill.

[4]. Wan, Y. H., Kng, K., Wang, S., \& Bond, F. (2014). Identifying idioms in Chinese translation. European Language Resources Association (ELRA). Retrieved from http://compling.hss.ntu.edu.sg/pdf/2014-lrec-chengyu.pdf

[5]. Fotovatnia, Z., \& Goudarzi, M. (2014). Idiom comprehension in English as a foreign language analyzability in focus. Social and Behavioral Sciences, 98, 499-503

[6]. Griffin, F. (2004). Idioms and back translation. Association for business communication. Business Communication Quarterly, 67(4).

[7]. Wang, L. \& Wang, S. (2013). A study of idiom translation strategies between English and Chinese. Theory and Practice in Language Studies, 3(9), 1691-1697

[8]. Nida, E. A. (2001). Language and culture: contexts in translating. Shanghai: Shanghai Foreign Language Education Press, pp. 28-40.

[9]. Nida, E. A. (1993). Language, culture, and translating (1st ed.). Shanghai Foreign Language Education Press.

[10]. Chen, L. (2010). On integrated translation approach of English idioms. Journal of Language Teaching and Research, 1(3), 227-230 